\title{
ORGANOGÊNESE FLORAL DO PESSEGUEIRO IN VTRO(')
}

\author{
WLSON BARBOSA $(2,3)$, FERNANDO ANTONIO \\ CAMPO DALL'ORTO(2,3) G MARIO OJIMA(2)
}

\begin{abstract}
RESUMO
Coletaram-se meristemas do pessegueiro 'Tropical' (Prunus persica L. Batsch) em 30 de outubro, 30 de novembro e 30 de dezembro de 1986 e 30 de janeiro e 28 de fevereiro de 1987 e cultivados in vitro. Aqueles coletados ate 30 de novembro desenvolveram-se vegetativamente, produzindo vitroplantas normais de pessegueiro. O mesmo năo ocorreu com os meristemas coletados em dezembro, janeiro e fevereiro, os quais se transformaram em bototes florais após quinze dias de cultivo in vitro. Evidenciou-se, assim, que o processo de indução floral para o pessegueiro 'Tropical' ocorreu em dezembro na regiảo de Jundiaí, SP $\left(23^{\circ} \mathrm{Os}\right.$ 'S.), uma vez que nenhuma vitoplanta se desenvolveu após esse periodo. Evidenciou-se, ainda, a irreversibilidade dos meristemas após o processo indutivo de diferenciaçăo floral.
\end{abstract}

Termos de indexaç⿸丆o: pessegueiro, Prunus persice L. Batsch, cultivar Tropical, meristema, cultura in vitro, organogênese floral, vitropianta.

\section{ABSTRACT \\ IN VITRO FLORAL ORGANOGENESIS OF 'TROPICAL'PEACH}

Meristems of 'Tropical' peach (Prunus persica L. Batsch) were collected on October 30th, November 30th and December 30th of 1986 and in January 30th and February 28th of 1987. These meristems were thereafter cultured in vitro. Those collected until November 30 th, produced vegetative buds and normal peach vitoplants. Different results were obtained with the meristems collected in December, January and February which developed floral buds after 15 days in culture. The results showed that floral induction

(1) Trabalho realizado com rocursos parciais da FAPESP e do CNPq. Recebido para publicaçăo em 16 de março o aceito em 12 de jutho de 1990.

(1) Seção de Fruticultura de Clime Temperado, lıuituto Agronómico de Campinas (IAC), Caixa Postal 28, 13001 Campinas (SP).

(3) Com bolse de pesquise do CNPq. 
occurs in December in the subtropical areas of Saxo Paulo State, Brazil. The hypothesis of floral bud irreversibility was confirmed; no vegetative bud developed in vito after the inductive period.

Index terms: Prunus persice L. Batsch, 'Tropical' peach, meristem, in vito culture, foral organogeriesis, vitoplant.

O processo da diferenciação floral do pessegueiro 6 escassamente investigado em regiőes de clima subtropical a tropical. Pesquisas são realizadas em zonas temperadas, onde o pessegueiro se comporta diferentemente em sua ontogenese reprodutiva (TUFTS \& MORROW, 1925; MONET, 1983; WARRINER et al., 1985; BARBOSA et al., 1990c).

Em trabalho recente, definiu-se a época da organogenese floral de pessegueiros adultos cultivados nas condiçōes climáticas da região de Jundial (SP), de latitude $23^{\circ} 08^{\prime S}$. Através da análise histologica das gemas, constatou-se que a iniciação floral se processa em janeiro, diferenciando sucessivamente nos dois meses seguintes as sépalas, as pétalas, os estames e o pistilo. Não foi possível, no entanto, através do método utilizado, definir a época da induçáo floral, quando o pessegueiro responde fielmente ao estímulo do ambiente, passando a fase reprodutiva (BARBOSA ot al., 1990b).

Objetivando obter tal conhecimento, cultivaram-se in vitro meristemas de pessegueiro coletados durante o perlodo provável de ocorrencia do fenomene. 0 trabalho baseou-se na hipotese de que as células meristemáticas respons -riann, in vitro, aos estŕmulos induzidos anteriormente na planta. Assim, a morfogénese do meristema, em meio de cultura, Indicaria a época provável da induçāo floral dos pessegueiros cultivados om regiōes definidas.

\section{Material e Métodos}

Utilizou-se o pessegueiro 'Tropical' (BARBOSA et al., 1989b), de maturação bem precoce, cultivado na Estação Experimental de Jundial, do Instituto Agronómico. As plantas adultas, conduzidas no espaçamento de $5 \times 2 \mathrm{~m}$, receberam os tratos culturais rotineiros da espécie (OJIMA et al., 1987). O dima da região é classificado como tropical de altitude, com cerca de 80 horas anuais de frio abaixo de $7^{\circ} \mathrm{C}$ (PEDRO JÚNIOR et al., 1979). A precipitação pluvial (mm) e a insolação (h) mensais no período experimental foram, respectivamente, de: 72,8 e 271 em outubro; 224 e 202,7 em novembro; 346 e 93,4 em dezembro de 1986; 369,8 e 192,5 em janeiro e 211,3 e 169,3 em fevereiro de $1987\left(^{4}\right.$ ).

(4) Dados obtidos na Seçāo de Climatologia Agricola, IAC. 
Cerca de $\mathbf{2 0 0}$ gemas de flanco, da porção central dos ramos, foram coletadas aleatoriamente, em toda a superfície da copa, em 30 de outubro, 30 de novembro e 30 de dezembro de 1986 e 30 de janeiro e 28 de fevereiro de 1987. Dissecaram-se as gemas em microscópio estereoscópico e os meristemas, sem esterilização, em número de cem por época de colheita, foram cultivados in vitro com a soluçāo salina de MURASHIGE \& SKOOG (1962), acrescida de: tiamina, $1 \mathrm{mg} /$; ácido nicotínico, $0,5 \mathrm{mg} /$; inositol, $100 \mathrm{mg} /$; glicina $250 \mathrm{mg} /$; glutamina, $500 \mathrm{mg} /$; asparagina, 250mg/; sacarose, 30g/ e ágar, $6 \mathrm{~g} /$ (BARBOSA et al., 1989a, 1990a). Objetivando proporcionar adequado desenvolvimento dos explantes, adicionaram-se a esse meio $10 \mu \mathrm{M}$ do regulador de crescimento, 6-benzilaminopurina (BAP), à exceçāo do cultivo de 30 de outubro. O pH foi elevado a 6,0 com KOH a $0,1 \mathrm{~N}$.

O material foi mantido em sala de crescimento, com fotoperfodo de 13 horas de luz artificial e temperatura de $28 \pm 2{ }^{\circ} \mathrm{C}$. Avaliou-se o experimento após o décimo dia de cultivo in vitro.

\section{Resultados e Discussăo}

Os meristemas do 'Tropical' desenvolveram-se rapidamente logo na segunda semana de cultivo in vitro. Constítuíram exceçäo, porém, os meristemas cultivados em 30 de outubro, sob meio ausente de regulador de crescimento. Nessas condiçōes, o desenvolvimento foi deficiente, justificando, assim, a adiçăo de 6-BAP nos cultivos dos meses seguintes. Dessa forma, todos os explantes coletados em 30 de novembro diferenciaram-se morfologicamente em tecido vegetativo (Quadro 1). As vitroplantas resultantes apresentaram, apos 30 dias de cultivo, de 1 a 3 pares de folhas normais, características da espécie.

Entretanto, os meristemas coletados em épocas subseqüentes (fins de dezembro, janeiro e fevereiro) deram origem a órgäos reprodutivos. Após quinze dias de cultivo in vitro, todos os explantes desenvolveram as partes florais, vistas ao microscópio estereoscópico: as sépalas, as pétalas, os estames e o plstilo. Transcorridos 30 dias, in vitro, os botöes florais estavam completamente desenvolvidos e aptos a antese. Posteriormente, no entanto, eles se oxidaram, na maioria, paralisando seu desenvolvimento in vitro (Quadro 1).

Por esses dados, sugere-se que o processo da indução floral do pessegueiro 'Tropical' ocorra em dezembro, nas condições ambientes da região de Jundial. Nessa época, caracterizada por dias quentes e longos, os pessegueiros atingem o crescimento exponencial $e$, dessa forma, são induzidos à diferenciação floral (BARBOSA ot al., 1990c).

Considerando-se que nos cultivos de fins de dezembro, janeiro e fevereiro, nenhuma vitroplanta foi detectada, conjetura-se que as células meristemáticas do pessegueiro, uma vez induzidas à organogênese floral, não mais se desdiferenciam. Para comprovar tal hipótèse, há necessidade do cultivo meristemático de outras variedades, de regiōes e de práticas culturais diferentes e, inclusive, em meios de cultura compostos dos variados reguladores de crescimento. 
QUADRO 1. Porcentagem de plantas e de botōes florais diferenciados in vitro com base em diferentes épocas de coleta de meristemas do pêssego 'Tropical'. Instituto Agronómico de Campinas, 1987

\begin{tabular}{|c|c|c|c|c|c|}
\hline \multirow{3}{*}{ Paråmetro } & \multicolumn{5}{|c|}{ Épocas de coleta e cultivo in vitro } \\
\hline & \multicolumn{3}{|c|}{1986} & \multicolumn{2}{|c|}{1987} \\
\hline & 30.10 & 30.11 & 30.12 & 30.01 & 28.02 \\
\hline Planta & $3^{(1)}$ & 100 & $\begin{array}{r}\% \\
0\end{array}$ & 0 & 0 \\
\hline Botão floral & 0 & 0 & 100 & 100 & 100 \\
\hline Oxidação & - & 0 & 95 & 91 & 100 \\
\hline
\end{tabular}

(1) Baixo desenvolvimento devido à ausencia de 6-BAP no melo de cultura.

Ressalte-se, nest pesquisa, o rápido desenvolvimento dos botões florais in vitro. Na planta, sob condiçőes naturais, a organogenese floral ocorre lentamente, necessitando mais de sessenta dias a completa formação do botăo no interior da gema (BARBOSA etal., 1990b). Tal diferença pode ter ocorrido pela ação da concentração de 6-BAP utilizada e pelas condiçōes de temperatura alta e totoperíodo longo, prevalecentes na cultura in vitro, ocorrendo as ültimas, tamberm, no campo durante o final da primavera e o início do verão.

\section{Agradecimento}

Os autores agradecem ao laboratorista Onivaldo Camargo o auxllio na preparação dos meios de cultura e o manuseio in vitro dos explantes.

\section{REFERENCIAS BIBLIOGRAFICAS}

BARBOSA, W.; CAMPO-DALL'ORTO, F.A. \& OJIMA, M. Concentraçöes de 6-benzilaminopurina no desenvolvimento in vito de embriöes de pessegos e nectarinas precoces. Bragantia, Campinas, 49(2):233-239, 1990a.

\& - Eliminação de anomalias fisiológicas, in vitro, de plântulas de pessegueiro. Bragantia, Campinas, 48/1):13-19, $1989 a$.

pomar compacto: III. Épocas de poda drástica na diferenciaçăo floral. Bragantia, Campinas, 49(1):147-155, 19906. 
BARBOSA, W.; CAMPO-DALL'ORTO, F.A.; OJIMA, M.; SAMPAIO, V.R. \& BANDEL, G. Ecofisiologia do desenvolvimento vegetativo e reprodutivo do pessegueiro em regiăo subtropical. Campinas, Instituto Agronômico, 1990c. 37p. (Documentos IAC, 17)

; OJIMA, M.; CAMPO-DALL'ORTO, F.A.; RIGITANO, O.; MARTINS, F.P.; CASTRO, J.L. \& SANTOS, R.R. Tropical': novo pessego de coloração vermelha intensa bem precoce para Săo Paulo. In: CONGRESSO BRASILEIRO DE FRUTICULTURA, 10., Fortaleza, 1989. Resumos. Forbleza, Sociedade Brasileira de Fruticultura, 1989b. p.57.

MONET, R, Le pecher: gendique et physiologie. Paris, INRA et Masson, 1983. $133 p$.

MURASHIGE, T. \& SKOOG, F. A revised medium for rapid growh and bioassays vith tobacco tissue cultures. Physiologia Plantarum, Copenhagen, 15:473497, 1962.

OJIMA, M.; CAMPO-DALL'ORTO, F.A.; BARBOSA, W. \& RIGITANO, O. PEssego (Prunus persice Batsch). In: CAMPINAS. Instituto Agronomico. Instruçöes agrlcolas para o Estado de Sazo Paulo. 4.ed. Campinas, 1987. p.168-169. (Boletim, 200)

PEDRO JÚNIOR, M.J.; ORTOLANI, A.A.; RIGITANO, O.; ALFONSI, R.R.; PINTO, H.S. \& BRUNINI, O. Estimativa de horas de frio abaixo de 7 e de $13^{\circ} \mathrm{C}$ para regionalizaçăo da fruticultura de clima temperado no Estado de São Paulo. Bragantia, Campinas, 38:123-130, 1979.

TUFTS, W.P. \& MORROW, E.G. Fruit-bud differentiation in deciduous fruits. Hilgandia, Berkeley, 1(1):1-14, 1925.

WARRINER, C.L.; JOHNSON, J.L. \& SMITH, M.W. Comparison of the initiation and development of 'Redhaven' peach flowers in standard and meadow orchard trees. Journal of the American Society for Horticultural Science, New York, 110(3):379-383, 1985. 